\title{
La transparencia de la razón. El alcance epistemológico de las categorías y el método de auto-indagación filosófica de la razón en la Ciencia de la Lógica de Hegel.
}

\author{
The Transparency of Reason. Epistemological Reach of Categories and \\ Reason's Method of Philosophical Self-Inquiry in Hegel's Science of Logic.
}

\author{
Por: Herszenbaun, Miguel* \\ CONICET-UNIPE/UBA \\ Ciudad Autónoma de Buenos Aires, Argentina. \\ Email: herszen@hotmail.com \\ Fecha de recepción: 03/07/2020 \\ Fecha de aprobación: 31/07/2020 \\ DOI: http://dx.doi.org/10.30972/nvt.1624534
}

\section{Resumen}

En este trabajo me propongo analizar cómo la discusión de Hegel de nociones centrales de la filosofía de Kant (tales como concepto, objeto, verdad, conocimiento, forma y contenido) lleva a replantear el alcance epistemológicamente legítimo de las categorías. Esta revisión se da junto con la advertencia de Hegel de un grave problema metodológico de la filosofía crítica: ésta es incapaz de justificar la pretensión de verdad del presunto autoconocimiento de la razón. Esto llevará a Hegel a reelaborar el método de auto-indagación de la razón, junto con las nociones antes indicadas. Finalmente, indicaremos cuáles son los requisitos - desde una perspectiva hegelianapara la verdad de un discurso filosófico: (1) admisión del conocimiento conceptual; (2) deducción inmanente basada en el concepto entendido como estructura sistemática; (3) deducción de la subjetividad; Y finalmente, el más importante, (4) la impensabilidad

\footnotetext{
* Doctor en filosofía (FFyL UBA) abogado (F. Der., UBA) y profesor de filosofía (FFyL UBA). Investigador del CONICET. Docente de la Facultad de Filosofía y Letras y de la Facultad de Derecho de la Universidad de Buenos Aires. Se especializa en la filosofía de Kant y Hegel, así como también en la filosofía moderna en general y la filosofía del Derecho. Su más reciente libro es La antinomia de la razón pura en Kant y Hegel (Alamanda, Madrid, 2018).
} 
de un modelo alternativo de la razón y la refutación de todo realismo. Con esto, se estará en condiciones de probar la legitimidad de la auto-indagación de la razón o transparencia de la razón.

Palabras clave: Hegel - Kant - Categoría - Método - Auto-indagación.

\begin{abstract}
In this paper, I analyze how Hegel's discussion of main notions of Kantian philosophy (such as concept, object, truth, knowledge, form and content) leads him to re-elaborate the epistemological reach of categories. This revision of categories comes with Hegel's notice of a serious methodological problem in Kant's critical philosophy: it is incapable of justifying the pretension to truth of the assumed self-knowledge of reason. This problem will take Hegel to re-elaborate reason's method of self-inquiry and the notions abovementioned. Finally, I will show the truth's requisites -according to a Hegelian perspective- of a philosophical discourse: (1) conceptual knowledge; (2) immanent deduction based on concepts understood as systematical structure; (3) deduction of subjectivity; last but most important, (4) impossibility to think an alternative model of reason and the refutation of all forms of realism. By accomplishing these requisites, the philosopher will be able to probe the legitimacy of reason's self-inquiry or the transparency of reason.
\end{abstract}

Keywords: Hegel - Kant - Category - Method - Self-inquiry.

\title{
Cómo citar este artículo:
}

APA: Herszenbaun M. (2020) La transparencia de la razón. El alcance epistemológico de las categorías y el método de auto-indagación filosófica de la razón en la Ciencia de la Lógica de Hegel. Nuevo Itinerario, 16 (2), 158-190. Recuperado de: (agregar dirección web) 
La transparencia de la razón.

El alcance epistemológico de las categorías y el método de auto-indagación filosófica de la razón en la Ciencia de la Lógica de Hegel.

Introducción

En el presente trabajo me propongo ofrecer una lectura de la Ciencia de la lógica. Esta lectura se hace en contraposición con la filosofía teórica kantiana. ${ }^{1}$ Comenzaremos considerando cómo Hegel pondera la filosofía teórica kantiana en lo referente a su comprensión de las categorías, el objeto, el conocimiento, la verdad y la intuición. Veremos que esta discusión sobre el alcance epistemológico de las categorías viene acompañada de una reflexión metodológica y meta-filosófica sobre cómo puede la razón saber sobre sí misma de manera legítima. En esto, se juega la posibilidad misma de todo proyecto filosófico. Veremos cuáles son los inconvenientes que Hegel ve en el desarrollo metodológico de la filosofía crítica y cómo se puede elaborar una respuesta a esta cuestión metodológica desde una perspectiva hegeliana.

Primera parte. La categoría, el objeto y la intuición. Una revisión hegeliana de los supuestos kantianos

En la presente sección, me propongo estudiar la posición de Hegel sobre algunos aspectos de la lógica trascendental kantiana con el objetivo de alcanzar una mejor comprensión de su proyecto lógico. Me ocuparé de la concepción hegeliana de la categoría y su relación con el objeto y la verdad. Para esto, tomaré como punto de partida el tratamiento hegeliano de la apercepción trascendental.

Hegel comienza admitiendo la legitimidad del descubrimiento kantiano: con el descubrimiento de la apercepción trascendental Kant ha descubierto la definición del concepto $-y$ con ello la definición del pensar puro- pero es incapaz de advertir la verdadera significación filosófica de su descubrimiento (Hegel, 1982, II, pp. 256-258; $2003,16-18)^{2}$

¿En qué consiste el descubrimiento kantiano? En la deducción trascendental, Kant pretende demostrar la validez objetiva de las categorías puras del entendimiento, esto es, que los conceptos puros del entendimiento tienen legítima aplicación al ser, a

\footnotetext{
${ }_{1}^{1}$ Para facilitar este diálogo, utilizaré un vocabulario filosófico lato, que me permita hablar de ambas filosofías a la vez. Términos como razón, ser, fundamento no deben ser tomados en su sentido técnico, salvo que por contexto se advierta lo contrario.

2 "I" y "II" indican el tomo en español de la Ciencia de la lógica.
} 
la experiencia. Esto se logra demostrando que las categorías son condiciones de posibilidad de la experiencia y, por tanto, son legítimamente aplicables a ella.

Aquí, se introduce la unidad sintética de la apercepción. Para conformar una experiencia unitaria, todas las representaciones que la conforman deben poder ser unificadas en una única conciencia. Para eso, se requiere una unidad aperceptiva sintética, es decir, una unidad de la conciencia capaz de unificar todas las representaciones del sujeto y de hacer que la representación formal yo pienso las acompañe (Kant, 2007, B131, B136-7-8-9, B150). ${ }^{3}$ Esto es el principio de la apercepción.

Las categorías son las reglas de esta síntesis, es decir, las actividades de enlace del múltiple brindado por la intuición y de su subsunción bajo la unidad de la conciencia. Es decir, son las formas que toma la síntesis de la apercepción, mediante las cuales las representaciones se vuelven representaciones de un mismo yo. Además, las categorías son representaciones puramente conceptuales de un objeto en general (B128). Sólo a través de ellas la conciencia tiene su polo objetivo, el objeto empírico recibe su unidad necesaria y el múltiple intuitivo es referido a un objeto unitario. Con esto, la representación se vuelve la representación de un objeto.

Ahora bien, ¿cuál sería el verdadero significado filosófico de la apercepción según Hegel? Según Hegel, la apercepción revela que el pensar puro es capaz de producir su propio objeto de conocimiento (Hegel, 1982, II, p. 258; 2003, 17-18). Lo que llamamos objeto, sólo lo es por la actividad de síntesis de la apercepción. El objeto es objeto sólo por el pensar. El descubrimiento kantiano del carácter sintético del pensar significa en su verdadero sentido filosófico que el pensar es sintético-originario y productivo: que el pensar puro es en esencia creador de su diferencia, de su propio objeto de conocimiento. En términos hegelianos, se dirá que el concepto ya no debe ser concebido como la representación de una nota común entre varios casos, sino como la actividad de creación de la diferencia que se subsume en él (Hegel, 1982, II, pp. 264,$277 ; 2003,22,32.1982$, I 265; 2008, 23). Como es sólo la conciencia con su actividad de síntesis la que puede conformar la unidad del objeto y brindarle

\footnotetext{
${ }^{3}$ La Crítica de la razón pura de Kant es citada indicando A y B para la primera y segunda edición respectivamente, seguidos por la paginación de la edición académica.
} 
La transparencia de la razón.

El alcance epistemológico de las categorías y el método de auto-indagación filosófica de la razón en la Ciencia de la Lógica de Hegel.

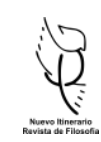

objetividad a las representaciones que de otra manera serían meramente subjetivas, con esto se descubre que el pensar posee en sí mismo un objeto de conocimiento.

Según esta interpretación del principio aperceptivo kantiano, la autoconciencia tendría en sí misma lo que más propiamente debe ser llamado objeto, implicando esto una alteración del alcance epistemológico de las categorías puras del entendimiento. Evidentemente, Hegel pretende darle al descubrimiento kantiano ciertas implicancias que el filósofo de Königsberg no admitiría. Veamos con más detalle esta discrepancia.

Se podría comenzar preguntándonos cuál es la razón, según Hegel, por la que Kant malinterpreta y tergiversa su descubrimiento y de qué manera lo hace. En términos generales, entiendo que Hegel piensa que Kant es incapaz de advertir el verdadero significado filosófico de su descubrimiento por la adopción irreflexiva de una serie de puntos de partida adoptados dogmáticamente.

El primer problema que Hegel encuentra es que Kant reconoce que el pensar produce su objeto, pero le niega al pensar puro y a su representación conceptual del objeto todo valor epistemológico. ¿Cuáles son los motivos para esto?

El motivo se encuentra en la conocida restricción del uso epistemológicamente legítimo de las categorías al terreno de la experiencia posible. O en otras palabras, esto se debe al carácter formal y vacío que Kant atribuye a los conceptos puros del entendimiento (Hegel, 1982, II, 270; 2003, 27). Las categorías puras son elementos conceptuales de carácter puramente formal. Sólo son capaces de imponer un enlace formal al múltiple intuitivo brindado por la intuición $y$, en consecuencia, sin dicho múltiple son incapaces de brindar la representación de un objeto determinado (Kant, 2007, B146 y B150). Por medio de las categorías, sólo tenemos la representación de la forma de un objeto en general, es decir, el mero pensamiento formal y vacío de un objeto en general. Con tal representación somos incapaces de conocer nada determinado. No podemos conocer por dichas representaciones puramente conceptuales objeto alguno de la experiencia, ni objeto más allá de la experiencia en tanto la representación formal carece de todo contenido ulterior. En otras palabras, sin la dación del dato intuitivo, el objeto producido por la apercepción es una mera representación formal (indeterminada) sin validez epistemológica. 
Como ya he adelantado, Hegel entiende que Kant llega a semejante conclusión debido a la adopción de un punto de partida dogmático que condiciona los resultados de su investigación. ¿Por qué se debe suponer que las categorías puras del entendimiento son formales y vacías cuando carecen del múltiple intuitivo? ¿Por qué se supone que el entendimiento puro es incapaz de brindarse a sí mismo el múltiple necesario para que la síntesis aperceptiva produzca un objeto determinado de conocimiento?

Aquí están operando dos presupuestos: El primero, la distinción entre forma y materia (o contenido) (cf. Houlgate, 2015, pp. 24-27). El segundo consiste en qué entiende Kant por "objeto". Comencemos por el primer punto.

La distinción entre forma y contenido conduce a su vez a diferenciar al pensar de su contenido pensado. Esta distinción entre la actividad de pensar y el contenido pensado tiene múltiples rasgos. Uno de ellos es la separación tajante entre la representación puramente formal yo pienso a través de la cual se representa el acto del pensar y el contenido representado (el múltiple intuitivo puro o empírico) que es dado por otra facultad (la sensibilidad) e integrado al pensar (es decir, subsumido bajo la unidad aperceptiva) a través de los múltiples enlaces formales de la que la apercepción es capaz.

Desde la perspectiva de Hegel, las categorías kantianas son por completo formales y la separación que Kant concibe entre forma y contenido es tajante. Señalar esto es pertinente, pues esta caracterización hegeliana de la lógica trascendental kantiana es fundamental para nuestra interpretación de Hegel.

Aunque cabe la posibilidad de que la caracterización que Hegel hace de Kant no sea del todo justa. Tal vez la distinción entre forma y contenido en Kant no sea tan tajante como Hegel cree: aun en la lógica trascendental kantiana, las categorías puras deben tener por sí mismas cierto contenido representacional propio y deben aportar a la representación epistemológicamente legítima cierto contenido semántico propio, independiente del contenido brindado por la sensibilidad. Esto quiere decir que aunque las categorías sean formales, poseen cierto contenido semántico propio (contenido no sensorial). Esto se advierte claramente cuando tenemos en cuenta las 
La transparencia de la razón.

\section{El alcance epistemológico de las categorías y el método de auto-indagación filosófica de la razón en la Ciencia de la Lógica de Hegel.}

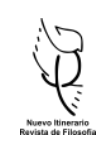

diferencias entre articular un múltiple bajo la forma del principio de causalidad y articularlo bajo la categoría de la acción recíproca o de la inherencia-subsistencia. Evidentemente, las categorías hacen un aporte semántico y representacional ${ }^{4}$.

Sin embargo, más allá de la exactitud con la que Hegel describe la filosofía kantiana, entiendo que en la propia Crítica de la razón pura hay una tensión y oscilación en lo que se refiere a acentuar o bien el carácter formal de las categorías o bien la aptitud de las categorías para representar conceptualmente (aunque sin validez epistemológica) al objeto en general. Y en esta tensión interna, cuanto más se acentúa el carácter formal de la categoría pura, más se acentúa la separación entre el pensar y el contenido pensado (objeto), lo que a su vez implica acentuar el límite epistemológico de la categoría pura, esto es, su ineptitud para brindar por sí misma un objeto de conocimiento legítimo. O también dicho al revés: cuanto más se acentúa la ineptitud epistemológica del uso teórico de las categorías puras, más se acentúa también su carácter formal y su distinción con aquello que sí sería contenido del pensamiento en sentido estricto. ${ }^{5}$

\footnotetext{
${ }^{4}$ La discusión sobre el carácter formal de las categorías y su contenido se vincula al problema de su relación con los juicios lógicos. Quienes sostienen que las categorías no poseen contenido, suelen reducirlas a la mera forma de los juicios de la lógica general. Esta discusión excede los límites de este trabajo, pero sostengo que la categoría no puede reducirse a la mera forma de su juicio correspondiente, sino que en ambos actúa la misma función; la categoría posee un contenido propio a través del cual no se piensa únicamente la forma de un juicio, sino un cierto contenido semántico representacional que permite el pensamiento o representación conceptual de un objeto en general o de algunos de sus rasgos ontológicos. Así, si por carácter formal de la categoría se entiende su reducción a la forma lógica general del juicio, discrepo con que las categorías sean formales. Si, en cambio, se admite el contenido semántico de la categoría, y en razón de la falta de intuición se habla de formalidad de la categoría (en la medida en que la categoría dé la forma del objeto, es decir, los rasgos ontológicos de un objeto en general), admitiría llamar formales a las categorías. Véase Paton, 1957, pp. 253-255, Longuenesse, 2000, p. 294, Wolff, 1963, p. 64, Reich, 1992, p. 9, Arias Albisu, 2010, pp. 112-113, Alves, 2008 pp. 118-119, Heimsoeth, 1963, p. 381. Herszenbaun, 2018, pp. 109-110, 309.

${ }^{5}$ El capítulo "Del fundamento de la distinción de todos los objetos en general en phaenomena y noumena" de la Crítica de la razón pura es un buen ejemplo de esta tensión. Kant intenta dejar en claro que las categorías puras no poseen un uso epistemológicamente legítimo, pues sin referencia a las condiciones sensoriales, no pueden brindar un objeto determinado. Sin embargo, para explicar esto, Kant abarca temáticas adyacentes que permiten caracterizar a las categorías. El texto es claro con respecto a las intenciones de Kant. Pero para cumplir con su objetivo, Kant por momentos asimila totalmente la categoría a la mera forma lógica o judicativa. Y por momentos reconoce que por medio de la categoría se representa algo (aunque este representar no tenga un carácter epistemológico válido). Parte de la complejidad del tema está dada por la manera en que Kant utiliza términos como uso y significado. La posición de Hegel consistirá, precisamente, en discutir y reivindicar lo que la categoría pura brinda por sí misma y su aptitud epistemológica. Véase Kant, 2007, A238-241/B298-B300, A2445/B302, A 247/B304.
} 
Lo que quiero decir es que el carácter formal de la categoría viene íntimamente vinculado a la incapacidad de la categoría de ofrecer un acceso epistemológicamente válido a un objeto de conocimiento. Si la categoría es formal, no puede brindar un objeto de conocimiento por carecer de un contenido que no es capaz de brindarse a sí misma. Y en este sentido, cuando más acentúa Kant su carácter formal, más se vuelve difusa su capacidad para representar aun siquiera al objeto en general.

A su vez, esta separación entre forma y contenido viene acompañada de una asunción dogmática de lo que debe entenderse por objeto. Con respecto a su concepción de objeto, Hegel presenta dos críticas contra Kant. La primera se refiere a la contraposición entre objeto de nuestras representaciones y cosa en sí, cuestión que no abordaremos para no desviarnos de nuestro interés inmediato (Hegel, 1973, p. 52). La segunda versa sobre la suposición dogmática de que el objeto de conocimiento debe ser dado a la intuición. Este es el punto que me interesa y que se vincula con el carácter formal de las categorías. Así como el acto del pensar es en sí mismo puramente formal -como ocurre en la lógica general- e incapaz de producir por sí mismo el contenido necesario para tener conocimiento, se entiende que el objeto del pensamiento, el contenido del pensamiento, debe ser dado por una facultad ulterior, la sensibilidad. En consecuencia, lo que es propiamente objeto es lo que excede al mero pensamiento y es dado por esta otra facultad.

Suponer que el único objeto de conocimiento legítimo es el brindado por la sensibilidad es un punto de partida dogmático que no ha pasado por el tamiz de la crítica. Podríamos hablar de un vestigio empirista. Aquí se presupone dogmáticamente tanto qué es objeto como qué es conocimiento. El único motivo para creer que el objeto brindado por la apercepción no deba ser aceptado como un legítimo objeto de conocimiento es presuponer dogmáticamente que las ideas de la filosofía están sometidas y supeditadas a la autoridad de la experiencia (Hegel, 1982, II, p. 265; 2003, 23). Esto es, sólo presuponiendo que el objeto debe ser el objeto de la sensibilidad y que se tendrá conocimiento sólo en tanto haya dación de dato intuitivo se puede considerar que el objeto dado por el pensar puro no es un objeto de conocimiento en sentido estricto. Presuponiendo lo que deben ser el objeto y el conocimiento se 
La transparencia de la razón.

El alcance epistemológico de las categorías y el método de auto-indagación filosófica de la razón en la Ciencia de la Lógica de Hegel.

degrada al objeto del entendimiento puro a una jerarquía inferior y sin legitimidad epistemológica.

En lugar de aceptar el descubrimiento fundamental de su filosofía crítica -esto es, que el objeto es siempre el objeto y el producto del pensar-, Kant recoge infundadamente restos empiristas y condiciona su descubrimiento fundamental a través de estas asunciones dogmáticas.

Así, quedan planteados los problemas que Hegel advierte en la lógica trascendental: se presupone que sólo es objeto en sentido estricto lo que esté dado en la intuición; y se presupone que las categorías son meramente formales (y se distinguen radicalmente de su contenido). Pareciera que cada uno de estos supuestos se apoya en el otro: Si el verdadero objeto de conocimiento sólo es el objeto de la experiencia posible (mediado por la intuición), el pensar puro ha de ser únicamente formal. No cabe concebir a las categorías más que como meramente formales toda vez que ellas, como actividades del pensar puro, sean incapaces de brindar un objeto. Si el objeto es objeto de la intuición, sin tal intuición el pensar queda vaciado de contenido y se reduce a una mera forma discursiva. Y al revés: Si el pensar puro es esencialmente formal, para tener un efectivo objeto de conocimiento se ha de requerir una facultad intuitiva que brinde un material concreto por pensar. En congruencia con su carácter formal y vacío, el pensar y sus determinaciones conceptuales quedan acotadas al terreno de la mera subjetividad, quedando la objetividad atada al dato exógeno (Hegel, 1982, I, p. 67; 2008, 35. Hegel, 1982, II, p. 260, 264; 2003, 19, 22-23. Hegel, 2002, pp. 420, 422, 424, 431). ${ }^{6}$

Hegel revisa estos supuestos atacando la caracterización kantiana del objeto (Hegel, 1982, II, 258-259; 2003, 17-18) y embarcándose en una reelaboración del concepto de verdad (Hegel, 1982, II, 269-270; 2003, 26-27). Como sabemos, la lógica trascendental de Kant comienza con su definición nominal de verdad entendida como correspondencia del concepto con el objeto. ${ }^{7}$ Hegel advierte que la verdad no está en

\footnotetext{
${ }^{6}$ Aquí Hegel indica el carácter subjetivo de la intuición y las categorías. Así, Kant vuelve a encontrarse con una contradicción, al degradar el estatuto del objeto empírico frente a la cosa en sí.

${ }^{7}$ Kant da una definición nominal de verdad entendida como correspondencia, luego de lo cual pasa a considerar a la lógica general y trascendental como criterios de verdad (2007, A58/B82-A60/B84, A62/B87). En tanto rechaza un criterio material de verdad y acoge uno formal, Kant parece dejar atrás
} 
el concepto (cuando concuerda con su objeto), sino que se da en la relación misma. Es en este sentido que afirma que si el concepto no concuerda con el objeto, tanto el concepto (sin objeto) como el objeto (sin concepto) son carentes de verdad (Hegel, 1982, II, p. 269; 2003, 26). En este uso peculiar del término verdad (al ser usado también en relación con el objeto y no sólo con el concepto), Hegel parece decirnos que sólo hay objeto si hay concepto y en razón de su relación con el concepto, es decir, en virtud de su relación con el pensar. En consecuencia, es inadmisible considerar a un elemento independiente del pensar como objeto. Es inadmisible concebir a la cosa en sí como objeto, pero también es inadmisible el considerar como objeto al dato intuitivo brindado por la sensibilidad con independencia del pensar.

Así como la verdad requiere dos extremos vinculados y sólo se da en esta relación, de igual manera únicamente hay concepto y objeto si se da esta relación. Sólo es objeto aquello que esté en relación con un concepto. En consecuencia, la concepción kantiana del objeto y de las categorías es en sí misma incongruente, contradictoria. Parte del supuesto de una discrepancia intrínseca entre objeto y categoría. Pero en razón de esta discrepancia, el objeto no sería objeto y la categoría no sería categoría. Cada uno de estos extremos es lo que es en razón del vínculo originario que los une. Hegel demuestra que uno no es tal sin el otro. La distinción entre forma y contenido que acompaña a la distinción entre concepto que piensa y objeto independiente del pensar dado en la sensibilidad (o contenido) se basa en una caracterización falaz del objeto (y el contenido), del conocimiento y de la categoría (la forma): ni el concepto ni el objeto son por sí solos capaces de verdad; ni el pensar ni el objeto son lo que son sin el otro. $\mathrm{Y}$, en congruencia, el pensar no puede ser nunca mero pensar formal sin objeto, sin contenido, así como no puede haber contenido sin el pensar.

En otras palabras, la doctrina kantiana de los elementos que separa y aísla a los elementos que constituyen el conocimiento es una doctrina que adultera la naturaleza

su concepción de la verdad como correspondencia. Sin embargo, desde la perspectiva de Hegel, Kant nunca abandona tal concepción de verdad, toda vez que la filosofía crítica se sostiene sobre datos exógenos al pensar y a su necesidad de referir el entendimiento puro a la experiencia posible. Sobre las consecuencias metodológicas de esto volveremos más adelante. 
La transparencia de la razón.

El alcance epistemológico de las categorías y el método de auto-indagación filosófica de la razón en la Ciencia de la Lógica de Hegel.

del mismo y, en última instancia, es una doctrina incapaz de verdad según sus propios criterios.

En razón de esta reelaboración de las nociones de categoría, objeto, conocimiento, verdad, forma y contenido, Hegel lleva a cabo una crítica a los límites epistemológicos trazados por Kant y habilita un conocimiento puramente conceptual. El pensar puro encuentra un objeto puramente conceptual, que es contenido inmanente del pensar y legítimo tema ${ }^{8}$ de conocimiento.

Pero a su vez, esta reelaboración conduce a un cambio de perspectiva en lo que hace a la metodología filosófica, esto es, a la justificación del conocimiento filosófico y al método idóneo para tal conocimiento. Esto es una pregunta por la validez y legitimidad del conocimiento filosófico, es decir, por el discurso que describe a la razón misma. ¿Qué acredita la validez y legitimidad de un discurso filosófico, del presunto auto-conocimiento de la razón?

En el caso de la filosofía crítica, Hegel ve que se supone una teoría correspondentista de la verdad, lo cual no sólo supone una dificultad a la hora de que se identifique adecuadamente el objeto del pensar puro, sino que además supone una dificultad metodológica. En pocas palabras, según Hegel, la filosofía crítica como presunto saber de la razón sobre sí misma carece del objeto idóneo (según sus propios parámetros) para validar o acreditar su descripción. Es decir, no hay modo de acreditar la veracidad del conocimiento trascendental entendido como saber de la razón sobre sí misma, ya que falta su debido objeto (según los propios parámetros del idealismo trascendental), i.e. el objeto intuible (Hegel, 1982, II, p. 270-1; 2003, 27). ${ }^{9}$ Y la

\footnotetext{
${ }^{8}$ Con los términos "tema" y "temático" me refiero al pensamiento referido a objeto o al contenido objetivo del pensamiento.

${ }^{9}$ Hegel dice sobre la posición kantiana "Si la razón pretende ser algo para sí, extraer la verdad de sí misma, será una razón trascendente, se remontará por sobre la experiencia, puesto que carecerá de la otra parte integrante, y engendrará tan sólo quimeras cerebrales", 2002, p. 424.

A esto se suma que en Enciclopedia parág. 10 (1997, pp. 111-112) y en Lecciones sobre la historia de la filosofía (2002, p. 221) Hegel señala la presunta incongruencia kantiana de pretender estudiar las facultades de conocimiento ("instrumentos") con independencia del conocer y no advirtiendo que estos "instrumentos" tendrían que conocerse a sí mismos, con lo cual serían factores condicionantes de nuestro conocimiento de ellos. Hartnack entiende que la crítica metafilosófica de Hegel a Kant consiste en que la reflexión sobre el alcance del conocimiento no sería, estrictamente, conocimiento. A esto Hartnack responde que la Crítica de la razón pura es un discurso prescriptivo y no descriptivo; la Crítica no pretende brindar conocimiento en el sentido tradicional cf. Hartnack 1987 pp. 78-80. Walsh (1987 p. 122) entiende que la crítica de Hegel a Kant consiste en que no se puede conocer el instrumento de
} 
experiencia posible que sirve como criterio de verdad empírica no puede ser el referente respecto del cual contrastar la veracidad del auto-conocimiento racional. ${ }^{10}$

A esto se suman otros problemas que Hegel advierte en la filosofía crítica. El presunto auto-conocimiento de la razón descripto en la filosofía crítica se encuentra condicionado por elementos exógenos a la razón, ya sea el dato intuitivo o ya sea la tabla lógica de juicios. Por otra parte, el idealismo trascendental se encuentra rodeado por antinomias irresolubles desde su marco teórico, como la oposición entre entendimiento y sensibilidad, razón teórica y razón práctica, incognoscibilidad de la cosa en sí y conocimiento de la libertad. Es decir, desde la perspectiva de Hegel hay múltiples indicios que indicarían la insuficiencia de la filosofía crítica para acreditar su legitimidad como auto-conocimiento de la razón.

Ahora bien, como habíamos adelantado, la reelaboración que Hegel lleva a cabo conduce a una solución de este problema. En la lógica hegeliana, la verdad se define como una correspondencia entre el pensar puro y su objeto inmanente, que no es otra cosa que el contenido inmanente del pensar, con lo cual los movimientos semánticos y conceptuales del pensar puro no son otra cosa más que el despliegue de su propio contenido semántico inmanente. Esta correspondencia implica que el pensar puro tiene un objeto con el cual se corresponde y permite la verdad de su saber de él, es decir, es objeto de conocimiento legítimo.

Esta correspondencia permite a su vez una solución metodológica al problema kantiano antes mencionado: el discurso filosófico como saber de la razón sobre sí misma ya no requiere corresponderse con un objeto intuible o medirse con un parámetro externo al pensar. El pensar puro puede corresponderse consigo mismo. Para eso, debe acreditarse la correspondencia entre el pensar filosofante, es decir, la razón que enuncia su presunto saber sobre su propia constitución, esto es, el discurso que describe a la razón y su objeto de presunto conocimiento, es decir, el pensar

conocimiento sin utilizar dicho instrumento de conocimiento. Así, la reflexión filosófica no logra conocer su objeto, o lo conoce de manera condicionada. En mi opinión, la crítica de la Enciclopedia y las Lecciones se complementa con aquella encontrada en la Lógica. En la Lógica, entiendo, se acentúa la inconsistencia del discurso filosófico (kantiano) que no puede cumplir sus propios parámetros de verdad, conocimiento y objetividad.

${ }^{10}$ Véase la nota siguiente. 
La transparencia de la razón.

El alcance epistemológico de las categorías y el método de auto-indagación filosófica de la razón en la Ciencia de la Lógica de Hegel.

descripto en el mismo discurso en cuestión, o sea, el pensar tematizado y descripto en la lógica.

Para que esta correspondencia se dé, el pensar tematizado en la lógica debe exponerse a sí mismo. No debe haber hiato entre el pensar tematizado, investigado, y la razón filosofante. Si el pensar que es tema u objeto de investigación en la lógica se expone a sí mismo, se da la correspondencia entre concepto (o pensar) y objeto, y se acredita con ello la verdad del propio discurso filosófico. Es decir, la verdad del autoconocimiento de la razón. Esto es, el discurso filosófico debe ser una auto-exposición de su propio contenido, que no es otra cosa que el pensar puro.

En conclusión, para resolver el problema que se presenta en la filosofía crítica a la hora de justificar el auto-conocimiento de la razón, se tiene que superar el desdoblamiento que se da en todo discurso. La razón filosofante debe acreditar que su tema presentado e indagado (se supone, ella misma) se corresponde con ella misma como razón indagante o filósofa (esto es, que fuera del pensar tematizado no hay otra razón distinta a ella). En otras palabras, la pregunta que se da aquí es cómo podemos saber si el desarrollo filosófico que la razón presenta al investigar al pensar en verdad se corresponde con lo que ella es, con su constitución. Según Hegel, en la filosofía kantiana, esto se resuelve tomando como marco de referencia a la experiencia posible. Pero esto implica acotar la indagación de la razón en función de ciertos conocimientos, clausurando a priori la posibilidad de otros conocimientos; en consecuencia, presuponer lo que la razón es y quedarse únicamente con ciertos rasgos de la subjetividad; y finalmente, supeditar el auto-conocimiento racional a ciertos datos que no son más que facta exógenos al pensar puro, con lo cual el saber filosófico o el saber propiamente racional estaría condicionado por hechos ajenos que en sí mismos le resultan inexplicables. ${ }^{11}$

\footnotetext{
${ }^{11}$ Aquí no me ocupo del método de la filosofía crítica según el propio Kant ni de evaluar si la lectura hegeliana de Kant es adecuada. Los criterios y el método que Kant utiliza para evaluar y determinar la verdad de su propio discurso filosófico se escapa a las intenciones del presente trabajo. Sin embargo, considero que esta lectura de Hegel sobre Kant permite comprender mejor aspectos epistemológicos y metodológicos de la lógica hegeliana, y también es concordante con la lectura que posteriormente el neokantismo hizo de la metodología de la filosofía crítica (Natorp, 1987, pp. 80-81). Aunque Kant no dice que la Crítica de la razón pura parta de un factum y retroceda a sus condiciones de posibilidad a través de argumentos trascendentales (tal como ha sido leída por influencia del neokantismo), sino que
} 
La reelaboración conceptual llevada a cabo por Hegel, en cambio, permite no sólo el conocimiento conceptual que redefine todos estos aspectos, sino que además permite pensar una metodología en la que la razón filosofante concuerde con su objeto de investigación (ella misma) de manera que se acredite la legitimidad de su saber de sí misma. En la sección siguiente, me propongo considerar cuáles son los requisitos que un discurso filosófico con tales pretensiones debe cumplir.

Segunda parte. La ampliación de la crítica metodológica: hacia la transparencia de la razón

En la sección precedente, nos hemos ocupado de desarrollar la crítica que Hegel dirige contra Kant en lo que respecta a sus errores a la hora de caracterizar la naturaleza del concepto y su relación con el objeto. Según esta crítica, la posición kantiana resulta incongruente de acuerdo con sus propios criterios. En primer lugar, Kant contradice el descubrimiento fundamental del idealismo trascendental, el carácter constituyente de la categoría respecto del objeto y el carácter sintético del concepto. En segundo lugar, de acuerdo con la propia caracterización kantiana de la verdad y del objeto, se revela que la filosofía trascendental (y más concretamente, su doctrina de los elementos) carece de verdad.

Esto nos llevó a una pregunta metodológica fundamental: ¿cómo acreditar que el discurso de la razón sobre sí misma es epistemológicamente legítimo? Al sostener Hegel que la representación o caracterización kantiana de la razón es no verdadera $(1982$, II, p. 269, 2003, 26) -lo que viene a ser una declaración respecto de la noverdad de la doctrina de los elementos-, Hegel está sosteniendo que la filosofía trascendental (como discurso de la razón sobre sí misma) no es capaz de verdad. Desde la perspectiva de Hegel, Kant es incapaz de demostrar lo que aquí llamaremos la

se procede por síntesis de los elementos que son esclarecidos e integrados, lo cierto es que la única forma que a mí parecer (siguiendo a Hegel) tiene Kant para acreditar la verdad de su investigación y descubrimiento de estas condiciones de posibilidad es remitir a aquello que ellas constituyan (i.e. la experiencia posible). Con lo cual la verdad de la doctrina de los elementos se ve por sus resultados o su congruencia con la experiencia posible. A fin de cuentas, depende de un factum con el que debe concordar (factum que debe presuponer y no puede explicarse a partir de la razón). 
La transparencia de la razón.

El alcance epistemológico de las categorías y el método de auto-indagación filosófica de la razón en la Ciencia de la Lógica de Hegel.

"transparencia"12 de la razón, esto es, la aptitud de la razón de volver su mirada sobre sí misma y hablar sobre sí con verdad.

Como hemos visto en la sección anterior, Hegel cree demostrar la verdad del discurso lógico, esto es, del discurso que el pensar enuncia sobre sí mismo. La clave de su verdad radica en que hay una doble concordancia: por un lado, el pensar pensado en la lógica y su objeto concuerdan, de modo tal que el pensar tematizado tiene en sí mismo un legítimo objeto de conocimiento. Por otro lado, la exposición lógica se hace desde adentro, no es otra cosa que el desarrollo inmanente de este mismo pensar y del desarrollo de su objeto necesario. Con lo cual, la razón filosofante no describe desde afuera a su objeto, sino que es idéntica al pensar pensado en la lógica y al objeto tematizado por dicho pensar. En otras palabras, el propio pensar objeto de la lógica se enuncia a sí mismo, garantizando que el discurso tenga objeto y su correspondencia con él.

En esta sección tomaré distancia del texto hegeliano para considerar cuáles serían los requisitos que harían posible esta transparencia de la razón. Con esta distancia, pretendo dispensarme de evaluar si efectivamente el texto hegeliano da cuenta de cumplir con estos requisitos. A pesar de esto, pretendo conservar una perspectiva hegeliana. Esto significa que consideraré cuáles son los requisitos que debe satisfacer un proyecto filosófico como el ideado por Hegel (tal como lo hemos caracterizado siguiendo sus críticas a Kant) para cumplir con el objetivo de una autoindagación de la razón que brinde un conocimiento objetivo y necesario.

Dicho en otras palabras, el hecho de que la razón hable de sí misma todavía no acredita que este discurso sea epistemológicamente válido. Es decir, Hegel parece decir que siempre que haya concordancia del discurso con su objeto está acreditada la verdad de ambos. ¿Pero cómo acreditamos que lo que la razón dice sobre sí misma sea, en efecto, conocimiento y no un desvarío? ¿Cómo acreditamos la necesidad de este saber de sí misma de la razón? ¿Cómo demostramos que la razón no se equivoca al describirse a sí misma? ¿No cabe acaso la posibilidad de que toda la enunciación filosófica que compone a la lógica especulativa sea el producto de una gran ilusión

12 Tal transparencia no implica un colapso de la razón sobre sí que suprima toda articulación, diferenciación interna o auto-mediación. 
trascendental o del engaño de un genio maligno? ¿Cómo demostramos esta concordancia entre el discurso enunciado y su presunto objeto? ¿Basta acaso con seguir los pasos del desarrollo del objeto tematizado (aquí, el pensar mismo) para confiar en que esta auto-exposición es verdadera y no ilusoria?

En otras palabras, para que el discurso lógico sea válido, es cierto que deberá haber una concordancia entre el pensar puro tematizado en la lógica, su objeto inmediato y el discurso filosofante, i.e. la razón que reflexiona y vuelve sobre sí. Pero todavía no hemos evaluado si hay requisitos ulteriores para que esta correspondencia ocurra (y para que en consecuencia la razón pueda hablar de sí con verdad). Pasemos, entonces, a ponderar los requisitos de la transparencia de la razón.

En términos generales, sostendré que la transparencia de la razón, esto es, la aptitud epistemológica de la razón respecto de sí misma y eventualmente la verdad de la enunciación de la razón sobre sí misma, tiene los siguientes requisitos: (1) Conocimiento conceptual. (2) Deducción inmanente y estructura sistemática del concepto. (3) Deducción de la subjetividad (lo que en Hegel conocemos como el pasaje de la lógica objetiva a la lógica subjetiva). (4) Límite de lo pensable y refutación de los realismos. Desarrollemos en qué consisten estos requisitos.

(1) En primer lugar, debe aceptarse el conocimiento puramente conceptual así como admitirse la existencia de un objeto puramente conceptual. Esto resulta evidente, ya que de lo contrario se impediría por principio catalogar como conocimiento al saber de sí de la razón. Sin conocimiento puramente conceptual, es decir, restringiendo el conocimiento a la intuición y catalogando únicamente como objeto epistemológicamente legítimo al objeto de la intuición se impide por completo el auto-conocimiento de la razón. Este es, precisamente, el núcleo de la discusión hegeliana de la naturaleza de las categorías kantianas: la constitución del objeto a cargo de las categorías significa que el ser del objeto sólo es en el concepto y por el concepto. En consecuencia, no hay motivos legítimos para asumir que el objeto no ha de ser conceptual o intelectual, es decir, que se requiere necesariamente de intuición o que el objeto de conocimiento legítimo debe ser acotado al terreno del dato intuitivo. Esto es lo que se demostró en la sección precedente: que la asunción 
La transparencia de la razón.

\section{El alcance epistemológico de las categorías y el método de auto-indagación filosófica de la razón en la Ciencia de la Lógica de Hegel.}

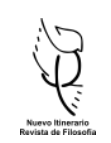

dogmática de que el conocimiento objetivo requiere intuición desnaturaliza el fundamental descubrimiento kantiano, i.e. el carácter constitutivo del concepto respecto de la objetividad. En congruencia con esto, asumir que no hay conocimiento conceptual implica necesariamente la imposibilidad de la razón -entidad únicamente inteligible- de conocerse a sí misma.

(2) El segundo requisito es la deducción inmanente. ${ }^{13}$ Con deducción inmanente nos referimos a un procedimiento de indagación por medio del cual la razón pueda conocerse a sí misma a través de una investigación interna, es decir, sin requerir el auxilio de un elemento exterior o un hilo conductor externo al pensar mismo, y que pueda llevar a cabo esta investigación de sí misma a partir de sí misma, dándose a sí misma el criterio de indagación y ejecutándolo por sí misma. ${ }^{14}$ Es decir, el criterio de indagación o el hilo conductor no le debe ser dado desde afuera o por otra facultad ni debe requerir otra facultad para llevar a cabo su indagación. ${ }^{15}$ Esta deducción inmanente también tendrá que ser completa o íntegra, es decir, permitir que la razón se recorra a sí misma por completo, sin que queden lugares inconexos o a los que no se pueda acceder a través de esta deducción (y requieran, por tanto, ser explicados acudiendo a otro elemento o a otro método), pero este punto será aclarado en las secciones siguientes. Aquí nos ocuparemos de los requisitos que exige esta deducción inmanente -qué se requiere para que ella sea posible-.

\footnotetext{
${ }^{13}$ Antes de Hegel, Reinhold (Hoyos, 2001, pp. 81 y ss.) y Fichte (Houlgate, 2006, pp. 23-24) creyeron necesario reelaborar la deducción metafísica de las categorías de Kant.

${ }^{14}$ Utilizo el término criterio para evitar el término principio que puede resultar equívoco, ya que Hegel no considera que la filosofía pueda comenzar por un primer principio, ni podemos encontrar un método preestablecido independiente del material mismo. En este sentido, Houlgate indica que la autoevaluación de la razón debe carecer de presupuestos, entre ellos el de un método (2006, pp. 27, 34, 42,48 ) y Nuzzo enfatiza la congruencia del desarrollo metodológico inmanente de la Lógica (que posee a la reflexión como la autoconciencia de la forma del método y no como un momento exógeno) (2011, pp. 114-116). Hegel insiste en que el método es inmanente al material propio del pensar, con lo cual la indagación lógica se hace a través del propio movimiento del pensar y su contenido. Elijo hablar de un criterio de indagación para referirme a aquellos requisitos generales que el método de indagación debe satisfacer para ser idóneo, sin que este criterio sea propiamente un método concreto o principio preestablecidos.

${ }^{15}$ Es conocida la objeción de Hegel a la deducción metafísica de las categorías de Kant, quien tomara la tabla de los juicios de la lógica general como hilo conductor para la deducción de las funciones del entendimiento. Según Hegel, esto es proceder de una manera empírica, pues se toma un mero dato histórico (el estado de desarrollo de una ciencia) como una verdad eterna y se intenta imponer esta forma estática y sin vida al pensamiento. En lugar de esto, la indagación filosófica debe hacerse desde adentro del propio pensar. Hegel, 1982, I, p. 70-1; 2008, 37-8. 1982, II, p. 256, 272; 2003, 16, 28. 2002, p. 430. 1997, parág. 42, p. 144.
} 
Para que este movimiento deductivo sea posible, es necesario que los conceptos sean (a) capaces de producir lo diferente de sí y (b) capaces de integrar lo diferente de sí en una estructura sistemática compuesta por relaciones o referencias semánticas internas. Es decir, en otras palabras, para acreditar la posibilidad de la deducción inmanente es necesario que los conceptos sean estructuras complejas, sistemáticas, sintéticas y dinámicas, compuestas por multiplicidad de elementos relacionados semánticamente entre sí.

La deducción es posible sólo si los conceptos tienen este carácter productor de su diferencia, si son capaces de remitir a dicha diferencia a través de múltiples vínculos semánticos $y$, con ello, integrarla en una estructura conceptual sistemática más compleja. Este carácter sistemático o integrador del concepto permitiría al pensar que lleva a cabo esta auto-indagación recorrerse a sí mismo de manera íntegra sin apoyarse en una guía exógena y lo demuestra Hegel en su tratamiento de la antinomia de la razón pura kantiana (Herszenbaun, 2018, pp. 479-480, 499, 568 y ss.) ${ }^{16}$.

En dicho tratamiento, Hegel demuestra que Kant ha hecho un descubrimiento legítimo sobre la naturaleza de la razón, pero que ha sido incapaz de comprender su verdadero significado filosófico, que la presentación kantiana de la antinomia es arbitraria, que Kant es incapaz de comprender el verdadero origen (lógico, conceptual) de la antinomia, que Kant acota indebidamente la cuestión antinómica al terreno de la cosmología racional y como un producto de la indebida interacción de la razón y la sensibilidad. El descubrimiento kantiano es, a los ojos de Hegel, acertado, pero mal comprendido por el filósofo de Königsberg (véase Herszenbaun, 2018, pp. 470 y ss., y Herszenbaun, 2017, pp. 38 y ss.).

Kant cree que la antinomia de la razón pura es el resultado del posicionamiento realista trascendental adoptado por la razón, que consiste en asumir que los objetos espacio-temporales, el tiempo y el espacio son cosas en sí. El realismo trascendental supone, en consecuencia, no abordar a la razón pura especulativa en su particularidad,

\footnotetext{
${ }_{16}$ Hegel, 1982, I, 71; 2008, 38 "Es un nuevo concepto, pero un concepto superior, más rico que el precedente; porque se ha enriquecido con la negación de dicho concepto precedente o sea con su contrario; en consecuencia lo contiene, pero contiene algo más que él, y es la unidad de sí mismo y de su contrario. Por este procedimiento ha de formarse, en general, el sistema de los conceptos, y completarse por un curso incesante, puro, sin introducir nada del exterior".
} 
La transparencia de la razón.

El alcance epistemológico de las categorías y el método de auto-indagación filosófica de la razón en la Ciencia de la Lógica de Hegel.

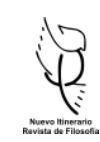

sino confundirla y mezclarla con la sensibilidad. Así, la antinomia que versa sobre el mundo espacio-temporal como una cosa en sí sólo se produce cuando se mezcla acríticamente la razón y sus principios puramente conceptuales con las formas de la sensibilidad. A su vez, Kant restringe el problema antinómico a la idea de mundo, es decir, al terreno de la cosmología racional.

Hegel, por el contrario, considera que Kant ha restringido innecesariamente su descubrimiento. Al acotar el problema antinómico al campo de la cosmología racional, no advierte que todo concepto es antinómico y no sólo las ideas de mundo. Según Hegel, Kant tampoco advierte que los conceptos no requieren de ninguna referencia a la sensibilidad para ser antinómicos. En otras palabras, para Hegel, la razón es antinómica en sí misma, todo concepto en su naturaleza es antinómico en sí mismo y, por tanto, no hay sólo cuatro antinomias o conflictos antinómicos, sino infinitos. Lo antinómico es un momento del desarrollo de lo conceptual. Y en última instancia, el carácter antinómico del concepto demuestra que cada concepto posee lados referidos semánticamente entre sí. La antinomia, comprendida en su verdadera naturaleza lógica o conceptual, consiste en que cada lado de un concepto, tomado en aislamiento, pretende concebir al objeto por sí mismo, constituirlo plenamente desde sí, pero al hacer esto se contradice, pues remite inevitablemente al momento opuesto y, en consecuencia, deshace su tarea de constitución del objeto. Esto demuestra que el concepto es una estructura sistemática, con momentos o lados relacionados semánticamente, productiva y dinámica, capaz de ampliarse, convertirse e integrar elementos.

Una deducción inmanente por medio de la cual la razón pueda indagarse a sí misma sin acudir a una guía externa, a un procedimiento impuesto desde afuera o partir de un principio exterior a sí misma, requiere la admisión del conocimiento conceptual (sin el cual la razón no puede decir conocerse a sí misma), que la dinámica de este conocimiento conceptual en el cual la razón no sale de su medio natural sea una dinámica capaz de entretejer e integrar conceptos, esto es, que sea capaz de crear redes conceptuales o sistemas (sin lo cual, un elemento conceptual descubierto no brindaría más que un conocimiento parcial de la razón), y por último, esta aptitud de 
integrar conceptos y formar redes requiere que los conceptos en cuestión estén vinculados, referidos unos a otros de alguna manera, y que puedan ser incorporados en una estructura conceptual superior. Como sabemos, Hegel piensa esta referencia de un concepto a otro a través de la negación, la contradicción, y la Aufhebung.

Sin estos requisitos, la deducción inmanente de las categorías del pensar puro es imposible $y$, en congruencia, es también imposible el auto-conocimiento de la razón. Sin esta deducción, no se tiene el hilo conductor inmanente al pensar para que el pensar se investigue a sí mismo.

Ahora bien, además esta deducción debe tener un carácter necesario. Al estudiarse a sí misma, la razón debe tener que pasar necesariamente de una categoría a la siguiente y así a la totalidad de la razón (alcanzando así no sólo un conocimiento de sus modos de pensar el objeto, sino un conocimiento completo de sí misma, de lo que es ser una razón). La necesidad del proceder de esta deducción demostraría que en esta investigación de sí misma la razón no incurre en errores ni en arbitrariedades, ni se encuentra sujeta a un error sistemático, a una ilusión trascendental o el hipotético engaño de un genio maligno. En otras palabras, que el saber de sí misma es necesario. Si esta deducción inmanente se demuestra necesaria, se acredita con eso también que es el camino del auto-conocimiento del pensar puro, es la garantía de la investigación íntegra de sí mismo. Pero hasta aquí, hemos explicado por qué es necesaria esta deducción inmanente para una auto-indagación de la razón y cuáles son sus requisitos. No hemos demostrado, en cambio, por qué y cómo su proceder es necesario (o cómo se prueba esta necesidad). Sobre esto volveremos en el último requisito.

(3) El tercer requisito que debe mencionarse es la deducción de la subjetividad. La deducción de la subjetividad es un momento fundamental de la deducción inmanente. En el caso de Hegel se trata del pasaje de la lógica objetiva a la lógica subjetiva. Este pasaje no es otra cosa que la instancia de la conversión de la sustancia en sujeto y, entre otras cosas, la refutación del spinozismo al final de la "Doctrina de la esencia". Es cierto que este pasaje sería un momento de la deducción inmanente antes 
La transparencia de la razón.

\section{El alcance epistemológico de las categorías y el método de auto-indagación filosófica de la razón en la Ciencia de la Lógica de Hegel.}

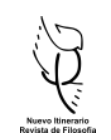

mencionada, pero por su importancia para el auto-conocimiento de la razón amerita ser considerado por separado.

¿Cuál es el aporte significativo de este momento de la deducción? El pasaje de la lógica objetiva a la lógica subjetiva o la demostración de la conversión de la sustancia en sujeto implica demostrar el agotamiento (un agotamiento inmanente y necesario del que hablaremos en el requisito número 4) del estudio de las categorías por medio de las cuales el pensar puro piensa su objeto inmanente y necesario como objeto, es decir, según categorías que permiten pensar únicamente el polo objetivo del pensar, y pasar a categorías que permiten por primera vez pensar adecuadamente al pensar como pensar. Este pasaje es, entonces, el descubrimiento de la subjetividad. ${ }^{17}$

Dicho en otras palabras, se debe evaluar si la deducción inmanente hace un pasaje fundado y legítimo de (a) el ámbito del despliegue sucesivo de categorías idóneas para pensar al objeto del pensar a (b) el ámbito de las categorías idóneas para pensar al pensar como pensar. Si no se demuestra la necesidad del pasaje de la lógica objetiva a la lógica subjetiva, entonces no hay cómo el pensar puro pueda hablar sobre sí mismo. No tendría los conceptos idóneos para ello. Resulta, por tanto, necesario para que la razón pueda hablar sobre sí misma que la deducción de las categorías de la

\footnotetext{
17 Cabría preguntar por qué un sistema filosófico o su exposición debe comenzar por la objetividad y descubrir la subjetividad y no al revés. Aunque sabemos que Hegel comienza su lógica con la inmediatez del ser y no con la subjetividad (que debe ser deducida) y esto se debe precisamente a la inmediatez requerida del punto de partida, la pregunta es legítima.

Se puede ensayar una respuesta retomando la distinción cartesiana entre método analítico y sintético. El método sintético es la exposición que se realiza partiendo de principios o axiomas y demostrando teoremas, al modo matemático. El método analítico, en cambio, expone la vía del descubrimiento (Descartes, 2011, pp. 115-7). Toda exposición según el método sintético carecerá de los fundamentos que condujeron al descubrimiento de los principios que dan razón y sustento al sistema que se expone. En el caso que aquí nos interesa, se trataría de un sistema que tiene como tema al pensar puro mismo (a diferencia de lo que pasaría, por ejemplo, con la geometría, que no requiere exponer la naturaleza del pensar, sino sólo ciertas determinaciones del espacio). Una exposición sintética del pensar supondría comenzar con el pensar y derivar de él todo lo que se funda en él. Pero tal exposición dejaría afuera las razones que llevan al descubrimiento del pensar, aunque éstas sean parte del pensar mismo, mostrando que la exposición sintética del sistema del pensar puro es eo ipso incompleta e infundada (aun si, paradójicamente, el primer principio fuera -concedamos- apodíctico). Esto quiere decir que aunque el sistema filosófico tenga su fundamento en la subjetividad, no puede comenzar inmediatamente por la subjetividad; debe descubrir la subjetividad y su lugar como fundamento. $Y$ tales descubrimientos forman parte del sistema en cuestión. En cambio, el comienzo por la objetividad parece menos problemático, siempre que no se pretenda que la objetividad se auto-fundamente. Un análisis más detallado de esta cuestión debería incluir un tratamiento de la imposibilidad (según Hegel) de comenzar el sistema con un principio y la inadecuación de las formas judicativas para expresar un contenido que en sí mismo es dialéctico, pero esto excede a las intenciones del presente trabajo.
} 
lógica subjetiva se pruebe como un momento necesario de la deducción inmanente antes mencionada.

En este pasaje necesario se encuentra también la refutación del spinozismo, forma culminante-según Hegel- del pensamiento sustancialista. Se demuestra que el momento último de la ontología no es sólo la sustancia, sino también el sujeto (la sustancia no queda suprimida, sino integrada a la subjetividad). Y se adquiere el aparato conceptual necesario para comprender que la lógica objetiva, las categorías por medio de las cuales se piensa el ser del objeto, son un elemento necesario del pensar puro, el contenido semántico inmanente del pensar puro. En otras palabras, se adquiere el concepto de concepto: noción que implica o permite ya no sólo pensar inmediatamente el objeto, pensar inmediatamente el contenido temático o pensado en la categoría, sino pensar propiamente a la categoría misma como tal cosa, como una categoría del pensar.

Es decir, el concepto (el descubrimiento del concepto de concepto) permite pensar o tematizar al pensar mismo. Descubrir que todas las categorías que presentan inmediatamente un objeto (como sustancia, como cantidad, cualidad, etc.), en verdad son pensar un objeto (o pensar un $x$ ), es decir, actividades de conceptualización del pensar puro. $Y$ por tanto, todos los pensamientos objetivos, es decir, todas las caracterizaciones categoriales del objeto, son momentos del pensar, de un pensar puro que no puede recurrir a otro elemento externo a sí al momento de explicar el origen de estas categorías. Y en consecuencia se descubre que estas categorías objetivas son un contenido semántico inmanente a dicho pensar. Desde esta nueva perspectiva, toda la lógica objetiva se revela como el desarrollo inmanente del pensar puro, como un contenido de las propias formas del pensar. Esta es la perspectiva que ofrece únicamente la lógica subjetiva.

Esto implica que el objeto del pensar es siempre y necesariamente un momento del pensar y que, en última instancia, el objeto es el pensar mismo (su polo objetivo necesario, un contenido semántico suyo). Lo que se descubre con la perspectiva abierta por la lógica subjetiva y la categoría de concepto. Con todo esto, se descubre que el movimiento de la deducción inmanente de las categorías es el 
La transparencia de la razón.

El alcance epistemológico de las categorías y el método de auto-indagación filosófica de la razón en la Ciencia de la Lógica de Hegel.

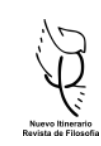

movimiento de auto-despliegue y auto-indagación del pensar, movimiento que en caso de revelarse necesario se tratará de una necesidad autoimpuesta por la razón (libertad). Se trata de un movimiento de auto-indagación del pensar que no puede concluir sin alcanzarse a sí mismo, esto es, sin alcanzar las categorías idóneas para pensarse a sí mismo como pensar y que con esta adquisición revela que las formas particulares que toma el pensar objetivo no son más que determinaciones inmanentes del pensar mismo.

Este requisito (el descubrimiento de la subjetividad al interior de la deducción inmanente) no sólo permite que la razón alcance los conceptos idóneos para pensarse a sí misma, sino también que adopte el punto de vista necesario para la correspondencia del objeto caracterizado en la Lógica y del pensar tematizado en ella. El resultado del pasaje de la lógica objetiva a la lógica subjetiva demuestra que el objeto del pensar puro concuerda con el propio pensar puro tematizado en la Lógica.

Si a esto se agregara una demostración concluyente de la necesidad de la deducción inmanente (y por tanto, también del pasaje de la lógica objetiva a la subjetiva), se demostraría también que la razón filosofante que enuncia la Lógica no es otra que el mismo pensar puro tematizado en la propia Lógica (es decir, que este pensar se expone a sí mismo). ${ }^{18}$ Si descubrimos que al tematizar e indagar los actos del pensar objetivo llegamos a las categorías propias para pensar al pensar mismo y se prueba la correcta exposición de este contenido, entonces quedaría acreditado necesariamente que esta indagación lógica es el pensar conociéndose a sí mismo de forma epistemológicamente legítima. Cumplir estos requisitos demostraría la verdad del discurso filosófico hegeliano y acreditaría la validez de su método.

Antes de pasar al requisito número 4, hagamos un resumen de lo anterior:

El pasaje de la lógica objetiva a la lógica subjetiva demuestra la concordancia de la razón tematizada en la lógica y el objeto de dicha razón. En contraposición a Kant, quien separaba la representación formal yo pienso del contenido pensado, Hegel demostraría de esta forma que todo contenido es contenido inmanente del yo (si lo

\footnotetext{
${ }^{18}$ Pippin (1989 pp. 37-38) y de Boer (2004 pp. 789, 803-804) comprenden la Lógica como una exposición reflexiva en la que el pensar se piensa a sí mismo y expone los requerimientos conceptuales para la concepción diferenciada de objetos, aunque Pippin entienda esto en términos epistemológicos y de Boer en términos ontológicos.
} 
decimos en términos kantianos) o que todo contenido temático del pensar, objetivo, es contenido del concepto, generado por una diferenciación interna del concepto (en términos hegelianos). El objeto y el pensar concuerdan en el terreno de la lógica, porque el desarrollo del ser del objeto no es otra cosa que el desarrollo del contenido inmanente del pensar. Cosa que Kant habría descubierto -al descubrir el carácter constitutivo de las categorías- pero habría pasado por alto -al dar preponderancia a la intuición-.

Ahora bien, si la deducción inmanente de categorías es correcta en la lógica hegeliana y se prueba el pasaje de la lógica objetiva a la lógica subjetiva, entonces también deberíamos dar por probada la concordancia entre la razón filosofante, es decir, la razón que enuncia el discurso filosófico, que habla sobre sí misma con pretensiones de verdad, y el contenido de dicho discurso. En este caso, el contenido de dicho discurso, su objeto, sería la razón tematizada en la lógica y su objeto de conocimiento. La correspondencia entre el discurso racional filosofante, la razón tematizada en la lógica y su objeto no se puede dar si el discurso filosofante enuncia "desde afuera" a su objeto, es decir, asumiendo que de un lado tenemos el discurso filosofante y del otro lado, como un objeto exterior y ajeno a este discurso, tenemos a la razón y su objeto de pensamiento. Si es cierto que el objeto es constituido por su concepto y que la verdad ha de ser en el terreno de la lógica la correspondencia del pensar consigo mismo, entonces la única forma en que el discurso filosofante pueda ser verdadero es si es un discurso que no se enuncia desde afuera de la investigación, sino desde adentro, es decir, que la razón estudiada sea, al mismo tiempo, la razón que se expone a sí misma.

De lo contrario, caeríamos nuevamente en el problema de la filosofía trascendental: ¿cómo acreditamos el valor de verdad del discurso filosófico trascendental? ¿Cómo acreditamos que la enunciación sobre cómo está constituido el sujeto cognoscente es verdadera?

Si no se prueba, previamente, que la razón puede saber de sí misma, se puede cuestionar la legitimidad y validez de todo el discurso filosófico. Ahora bien, no se 
La transparencia de la razón.

El alcance epistemológico de las categorías y el método de auto-indagación filosófica de la razón en la Ciencia de la Lógica de Hegel.

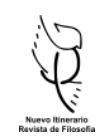

puede probar, antes de estudiar qué es la razón, si la razón puede o no puede hablar legítimamente sobre sí misma.

La única forma de probar esto es que la propia investigación temática sobre la razón (es decir, la investigación en la que la razón misma sea el objeto considerado) lleve necesariamente a admitir (no que lo suponga) que la razón puede hablar sobre sí misma válidamente y que lo que dice sobre sí misma es verdadero. En otras palabras, el discurso filosofante o la descripción que la razón filosofante hace de la razón estudiada en la lógica -en última instancia, de sí misma- debe formar parte de la propia investigación temática o, en otras palabras, debe surgir como un momento del desarrollo de dicha investigación temática: en el desarrollo de la deducción inmanente, a través de la cual se despliegan las formas de la razón, debe surgir como un momento necesario suyo el saber filosofante, el saber de la razón sobre sí misma, sobre aquella razón tematizada y desplegada en la propia deducción inmanente.

Así, el camino que parte de una investigación temática de la razón, concluye en una justificación metodológica de la propia auto-indagación realizada. Esto quiere decir que la investigación comienza no presuponiendo qué es la razón y por qué ella puede hablar con verdad sobre sí misma, sino que se comienza inmediatamente con las determinaciones de la razón por medio de las cuales ella piensa a su objeto. Esto no es otra cosa que comenzar con las notas más inmediatas de la razón misma, en tanto ella misma es objeto tematizado en la investigación lógica. Pero debe concluir con la acreditación de la transparencia de la razón para sí misma, es decir, acreditando la verdad del discurso filosofante sobre la razón, discurso que debe emerger como un resultado necesario en la propia investigación que toma por tema u objeto a la razón en sus determinaciones inmediatas y referidas a objeto.

Ahora bien, como veremos en el requisito número 4, este resultado depende de la acreditación de la plenitud de la investigación y sólo así opera metodológicamente como el levantamiento y confirmación de los supuestos iniciales (ya sea el punto de partida de la investigación temática como el decurso metodológico). Como también veremos a continuación, si no se logra esto, entonces el discurso lógico conserva, en razón de una insuficiencia metodológica, un hiato o 
dualismo en su interior que rompe toda posible concordancia entre el concepto y su objeto, o en otras palabras, entre el pensar y el pensar: El pensar tematizado y el pensar filosofante se disocian y la razón nunca alcanza una auto-indagación completa ni puede llamar a este saber de sí conocimiento.

Pasemos, entonces, a considerar el último requisito que permite la autoindagación de la razón, aquel en que se pone en juego la completitud de la indagación lógica y, con ello, brinda su triunfo o su fracaso.

(4) El cuarto requisito es la demostración de los límites de lo pensable y la consecuente refutación (y superación) de los realismos. Este último ítem hace a aspectos centrales de los requisitos anteriores y aquellos no pueden probarse sin éste.

La deducción inmanente y el pasaje a la lógica subjetiva tienen un papel central en lo que hace al proyecto lógico como un todo y a su propia justificación metodológica. Como sabemos, si no se demostrase la necesidad de la dinámica que mueve internamente a la deducción inmanente y que lleva al pasaje hacia la lógica subjetiva, el desarrollo de la lógica quedaría fallido. Se trataría de una caracterización de la razón cuya validez sería cuestionable. ¿Qué prueba podríamos ofrecer para demostrar que esta deducción no es una ensoñación, una ilusión trascendental, un engaño del genio maligno? ¿Cómo se prueba que esta auto-indagación de la razón es una descripción más confiable que o preferible a otras?

El cuarto requisito es la demostración de haber alcanzado los límites de lo pensable, es decir, demostrar la impensabilidad (permítaseme el neologismo) de una descripción alternativa de la razón. Esto viene acompañado a su vez de su contracara: la refutación de todos los realismos, esto es, la demostración de la inexistencia de resto ontológico alguno ajeno al objeto del pensar. Veamos esto más detenidamente.

Una auto-indagación de la razón que no sólo describa a la razón, sino que se justifique metodológicamente a sí misma debe demostrar su necesidad y su carácter absoluto. Tal carácter absoluto al que nos referimos consiste en demostrar que la razón es incapaz de pensar y asumir un sistema alternativo, es decir, una descripción alternativa. Se debe tratar, entonces, de una investigación en la cual al alcanzarse el punto final de la misma, se haya demostrado la imposibilidad de toda alternativa, la 
La transparencia de la razón.

El alcance epistemológico de las categorías y el método de auto-indagación filosófica de la razón en la Ciencia de la Lógica de Hegel.

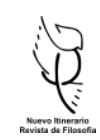

exclusión absoluta de toda otra descripción alternativa ${ }^{19}$. Si la conceptualización que la razón hace de sí misma no puede ser suplida por una conceptualización alternativa, este conocimiento de la razón sobre sí misma es necesario (para sí misma y para cualquier otro intento de caracterización de la razón).

Aquí podría entrar en juego una consideración sobre los supuestos del comienzo de la Lógica o su presunta falta de supuestos. Uno podría objetar que la necesidad de la conclusión depende de los supuestos de los que se parta, con lo cual la conclusión no posee una necesidad absoluta, sino sólo relativa a la validez de los supuestos. Sin detenerme en el complejo problema del comienzo de la lógica, señalo únicamente que no creo que sea necesario que la lógica carezca de supuestos, basta con que la lógica pueda justificar de una determinada manera estos supuestos iniciales en su conclusión. Más precisamente, si la conclusión de la lógica demuestra la impensabilidad de un pensar alternativo, más allá de cualquier supuesto a admitir (es decir, como veremos más abajo, si el proceder de la investigación demuestra la refutación (y superación) de todo modelo alternativo de la razón y la inadmisibilidad de todo otro comienzo o supuesto posible). ${ }^{20}$

A esto resulta necesario agregar dos problemas posibles. (a) El primero de ellos, cómo demostrar la impensabilidad de una caracterización alternativa de la razón. (b) El segundo problema, si acaso no cabe la posibilidad de que la razón sea incapaz de pensarse a sí misma de una manera alternativa y que, de todas formas, esta autocomprensión o auto-caracterización sea falsa, no se corresponda con el ser de la razón, con lo que la razón en efecto es. Como si dijéramos: el que la razón deba pensarse de cierta manera no prueba que la razón en efecto sea de esa manera. Cabe la posibilidad de que la razón resulte incapaz de saber cómo ella misma es y que quede encerrada en una auto-consideración sólo subjetivamente necesaria.

En cuanto al primer problema, debe señalarse que Hegel sostiene que el avance a lo largo de la deducción inmanente se da a través de una demostración de la insuficiencia de cada uno de los momentos precedentes alcanzados, esto es, a través

\footnotetext{
${ }^{19}$ Sobre el carácter inmanente de dicha refutación, véase Hegel, 1982, II, p. 253-254; 2003, 14-15.

${ }^{20}$ Este es el método de demostración según Neuhouser (1990, pp. 58-59) de la filosofía de Fichte a partir de 1797.
} 
de una refutación inmanente y según los propios supuestos asumidos en cada una de las posiciones filosóficas adoptadas y los momentos lógicos presentados. En otras palabras, el avance de la descripción que la razón hace de sí misma se ve impulsado por las contradicciones a que se llega con cada una de las descripciones alternativas (en muchas ocasiones, descripciones del conocimiento del objeto, pero, en consecuencia, también descripciones de la razón y del auto-conocimiento de la razón). Este es el elemento central que garantiza la necesidad de la deducción inmanente y también la imposibilidad de ofrecer un esquema alternativo de la razón: En este proceso, antes del final, todos los esquemas alternativos ya han sido refutados según sus propios criterios y han conducido a plasmar el sistema final, absoluto, frente al cual no hay alternativa posible. Es decir, este final supone la exclusión de una caracterización alternativa y de un comienzo por un supuesto diferente.

En cuanto al segundo problema, aquí es donde entra en juego la contracara del límite de la pensabilidad: la refutación de todos los realismos. El desarrollo completo de cómo la razón se piensa a sí misma -completo porque no puede haber un modelo alternativo- exige también la refutación de todos los realismos, esto es, la refutación de toda forma de concebir al objeto (o al ser) como autónomo respecto del pensar y de toda forma de concebir un resto ontológico incognoscible más allá del pensar. De lo contrario, de subsistir alguna forma de realismo, siempre cabría la posibilidad de postular, frente a un determinado modelo de la razón, un resto ontológico exógeno al modelo, lo que equivale a afirmar que el modelo no es absoluto: hay algo más que no fue conceptualizado, abarcado por la auto-indagación de la razón. Y, por tanto, la razón misma puede estar entre ese algo más, permitiendo esto que ella sea de otra manera a como ella misma se concibe.

Toda posición realista deja abierta la posibilidad de un modelo alternativo de la racionalidad. En tanto plantea un resto ontológico no conceptualizado o no sometido a la autoridad y poder del concepto, también cabe la posibilidad de que la razón sea por fuera de la conceptualización de sí misma. En otras palabras, el resto ontológico no conceptualizado o no dependiente del concepto deja planteado un terreno ontológico en el que la razón puede ser, aun con independencia de cómo se la ha conceptualizado 
La transparencia de la razón.

El alcance epistemológico de las categorías y el método de auto-indagación filosófica de la razón en la Ciencia de la Lógica de Hegel.

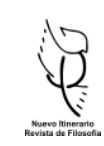

hasta el momento; deja abierta la posibilidad de un modelo alternativo de la racionalidad (desconocido). Toda forma de realismo trascendental -sea como sea que se piense ese ser en sí- es un desafío a la manera pensada o conceptualizada de concebir el ser, permite que la razón sea de otra manera a la concebida y es, por tanto, un atentado a la impensabilidad de una caracterización alternativa de la razón.

En esto consistiría la necesidad subjetiva de la auto-consideración de la razón a la que nos referíamos más arriba: la razón se ve conducida a una consideración de sí misma que a ella se le presenta como necesaria, pero que tal vez sea necesaria sólo de manera subjetiva, cabiendo la posibilidad de que ella sea de otra manera a como se concibe a sí misma sin que ella siquiera lo sepa ni sea capaz de saberlo.

Este requisito exige, entonces: (a) que se alcance la manera última de concebirse la razón a sí misma. Manera última dado a (a.1) que no posee esquema o modelo alternativo y a (a.2) que no puede ser reemplazado por un modelo de la razón que parta de otros supuestos (pues en el desarrollo, estos otros supuestos ya fueron refutados internamente e integrados como momentos necesarios pero parciales del propio desarrollo del movimiento de auto-comprensión de la razón). (b) Que se obture toda posibilidad de plantear un terreno ontológico exógeno al pensar. Muchas de las caracterizaciones alternativas de la razón que han sido refutadas ya sea en la Lógica como en la Fenomenología suponen la adopción de un punto de vista realista trascendental. Si se acredita la refutación sucesiva de cada una de las formas de realismo, se obtura toda posibilidad de plantear una concepción del ser como ajeno al pensar, esto es, de postular un resto ontológico fuera del concepto. ${ }^{21} \mathrm{Si}$ bien en la lógica se presupone la identidad de categoría y objeto (como resultado de la Fenomenología), el mismo proceso de desarrollo del contenido semántico de la categoría demuestra esta identidad (a través de la necesidad del surgimiento del pensar en función de las categorías inmediatas del objeto). Esta demostración cancela

\footnotetext{
${ }^{21}$ La refutación de los realismos se identifica también con la demostración de la necesidad del pasaje de la lógica objetiva a la lógica subjetiva o la necesidad de la conversión de la sustancia en pensar. Si el ser es siempre el ser del pensar, debe admitirse la conversión de la sustancia-objeto en subjetividad, i.e. que en el ser surja el pensar y que gracias a eso el pensar adopte las categorías idóneas para pensarse como lo que es: pensar.
} 
toda admisibilidad de concebir un ser fuera del pensar y da la garantía de la refutación de todos los realismos.

Con esto, llegamos también a la demostración del carácter auto-constitutivo de la razón. La refutación de los realismos es la contracara necesaria de la demostración de la imposibilidad de pensar una caracterización alternativa de la razón. Si se refutan todos los realismos, no se puede plantear la posibilidad de que la razón no sea como ella misma se piensa. Es decir, no sólo no hay modelo alternativo de acuerdo con el cual la razón hubiese de pensarse (conclusión que podría tener una necesidad meramente subjetiva), sino que más aún se garantiza la adecuación de este modelo (es decir, la necesidad objetiva de esta descripción de la razón). Si no hay resto ontológico más allá del pensar, siempre el ser es el ser del pensar y según cómo el pensar lo piense. Si la razón se piensa según un determinado esquema, sistema o modelo (absoluto, sin alternativas coherentes), la razón ha de ser tal como se piensa, porque no es viable argüir una posición realista que deje un terreno ontológico por fuera de tal concepción racional. La refutación de los realismos y la demostración de haber alcanzado el límite de la pensabilidad (de la razón sobre sí misma) conducen a la demostración del carácter auto-constitutivo o auto-constituyente de la razón y de su método de auto-indagación. La razón no se mira a sí misma y se describe según una necesidad meramente subjetiva, según una creencia o una opinión; la razón alcanza un punto de vista absoluto, universal, por completo necesario e inevitablemente se constituye a sí misma siendo tal y como se piensa ser. Su descripción es en verdad su auto-generación o auto-constitución.

En esto consistiría demostrar la transparencia de la razón.

\section{Conclusiones}

El trabajo hegeliano sobre las nociones de concepto, objeto, conocimiento, forma y contenido llevan a un replanteo del alcance epistemológico de las categorías según el cual se admitiría un conocimiento puramente conceptual de carácter objetivo y epistemológicamente legítimo. A su vez, esto conduce al planteo de un problema metodológico. Según las anteriores nociones, la filosofía trascendental no puede 
La transparencia de la razón.

El alcance epistemológico de las categorías y el método de auto-indagación filosófica de la razón en la Ciencia de la Lógica de Hegel.

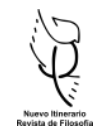

justificar su pretensión de verdad ni justificarse metodológicamente. En virtud de este problema, hemos pasado a considerar cuáles son los requisitos para la verdad de un discurso filosófico desde una perspectiva hegeliana, a saber: la admisión del conocimiento conceptual, de una deducción inmanente basada en una comprensión del concepto según la cual se le atribuye una estructura sistemática, la deducción de la subjetividad a partir de las categorías objetivas, demostrándose con esto que las categorías objetivas son el contenido inmanente del pensar puro. Finalmente, se llega al requisito más significativo. El desarrollo metodológico debe demostrar la imposibilidad de todo otro modelo alternativo de la razón y la imposibilidad de todo realismo. Si se prueba todo esto, el discurso filosófico se prueba a sí mismo más allá de toda posible objeción. Se prueba el auto-conocimiento de la razón. Y esto prueba además la auto-constitución de la razón: la razón respeta sólo sus leyes y se forma según éstas, nada externo la impulsa o condiciona. La razón es transparente a sí misma en términos epistemológicos (es capaz de hablar sobre sí misma con verdad) y ontológicos (no hay resto ontológico que empañe su reconciliación reflexiva consigo misma). 


\section{Bibliografía}

Alves, Pedro M. S. (2008). "The Concept of a Transcendental Logic", en V. Rohden, R. R. Terra, G. A de Almeida y M Ruffing (eds.), Recht und Frieden in der Philosophie Kants. Law and Peace in Kant's Philosophy. Akten des X. Internationalen Kant-Kongresses, tomo 5, (pp. 113-125), Berlin: Walter De Gruyter.

Arias Albisu, Martín (2010). "Algunas observaciones acerca del significado lógico de las categorías puras", Tópicos, n. 20, pp. 101-118.

Descartes, René (2011). Meditaciones metafísicas segundas de las objeciones y respuestas, Madrid: Gredos.

de Boer, K. (2004) "The dissolving force of the concept: Hegel's ontological logic", The Review of Metaphysics, Vol. 57, No. 4, pp. 787-822.

Hartnack, J. (1987), "Categories and things-in-themselves", Priest, Stephen, Hegel's Critique of Kant, (pp. 77-86). Oxford: Clarendon Press.

Hegel, G. W. F. (1982). Ciencia de la lógica, 2 tomos, (traductor R. Mondolfo), Buenos Aires: Ediciones Solar.

Hegel, G. W. F. (2003). Wissenschaft der Logik. Die Lehre vom Begriff, Hamburg: Felix Meiner Verlag.

Hegel, G. W. F. (2008). Wissenschaft der Logik. Die Lehre vom Sein, (1832), Hamburg: Felix Meiner Verlag.

Hegel, G. W. F. (1973). Fenomenología del espíritu, (traductor W. Roces), México: Fondo de Cultura Económica.

Hegel, G. W. F. (2002). Lecciones sobre la historia de la filosofía, tomo III, (traductor W. Roces), México: Fondo de Cultura Económica.

Hegel, G. W. F. (1997). Enciclopedia de las ciencias filosóficas en compendio, (traductor R. Vals Plana), Madrid: Alianza Editorial.

Heimsoeth, Heinz (1963). „Zur Herkunft und Entwicklung von Kants Kategorientafel“, Kant-Studien, 54, 1-4, pp. 376-403.

Herszenbaun, Miguel (2018). La antinomia de la razón pura en Kant y Hegel, Madrid: Alamanda.

Herszenbaun, Miguel (2017). "La lectura hegeliana de la antinomia de la razón pura", Ideas y Valores, 66 (165), pp. 35-56.

Houlgate, S. (2015). "Hegel's Critique of Kant", Proceedings of the Aristotelian Society Supplementary Volume LXXXIX, pp. 21-41. 
La transparencia de la razón.

El alcance epistemológico de las categorías y el método de auto-indagación filosófica de la razón en la Ciencia de la Lógica de Hegel.

Houlgate, Stephen (2006). The Opening of Hegel's Logic. From being to infinity, Indiana: Purdue University Press.

Hoyos, Luis Eduardo (2001). El escepticismo y la filosofía trascendental. Estudios sobre el pensamiento alemán a fines del siglo XVIII, Bogotá: Siglo del Hombre Editores y Universidad Nacional de Colombia.

Kant, Immanuel (2007). Crítica de la razón pura, (traductor M. Caimi), Buenos Aires: Colihue.

Longuenesse, Beatrice (2000). Kant and the capacity to judge: sensibility and discursivity in the transcendental analytic of the Critique of pure reason, Princeton: Princeton University Press.

Natorp, Paul (1987). Kant y la escuela de Marburgo, México: Editorial Porrúa.

Neuhouser, Frederick (1990). Fichte's Theory of Subjectivity, Cambridge: Cambridge University Press.

Nuzzo, Angelica (2011). "Thinking Being: Method in Hegel's Logic of Being", en Houlgate, S., Baur, M., A Companion to Hegel, (pp. 111-138). Oxford: Blackwell Publishing.

Paton, H. J. (1957). "Formal and transcendental logic", Kant-Studien, 49, pp. 245-263.

Pippin, R. (1989), Hegel's idealism. The satisfactions of self-consciousness, Cambridge: Cambridge University Press.

Reich, Klaus (1992). The Completeness of Kant's Table of Judgments, California: Stanford University Press.

Walsh, W. H. (1987). "The idea of a critique of pure reason: Kant and Hegel", Priest, Stephen, Hegel's Critique of Kant, (pp. 119-133). Oxford: Clarendon Press.

Wolff, Robert Paul (1963). Kant's Theory of Mental Activity. A Commentary on The Transcendental Analytic of The Critique of Pure Reason, Cambridge: Harvard University Press. 